\begin{tabular}{lc} 
Sharif University of Technology & Scientia Iranica \\
SCIENTIA & Transactions F: Nanotechnology \\
I RAN ICA & http://scientiairanica.sharif.edu \\
\hline
\end{tabular}

\title{
Effect of thermal radiation on MHD micropolar Carreau nanofluid with viscous dissipation, Joule heating, and internal heating
}

\author{
S.M. Atif*, S. Hussain, and M. Sagheer \\ Department of Mathematics, Capital University of Science and Technology, Islamabad, Pakistan.
}

Received 24 August 2018; received in revised form 15 June 2019; accepted 2 September 2019

\author{
KEYWORDS \\ Magnetohydrodynamics; \\ Micropolar Carreau \\ nanofluid; \\ Joule heating; \\ thermal radiation; \\ Viscous dissipation.
}

\begin{abstract}
The aim of the present study is to analyze the magnetohydrodynamic micropolar Carreau nanofluid flow past a stretching sheet. Viscous dissipation, internal heating, Joule heating, and linear thermal radiation effects are also incorporated into the energy equation. The system of governing PDEs is transformed into the ODEs by invoking the similarity transformation. The shooting method is implemented to solve the system of ODEs. The influence of pertinent parameters on flow distributions is analyzed graphically and discussed in detail. The fluid motion upsurges for the larger values of the Weissenberg number and the material parameter, while the reverse situation is studied in the thermal and concentration profiles.
\end{abstract}

(C) 2019 Sharif University of Technology. All rights reserved.

\section{Introduction}

Non-Newtonian fluids with magnetohydrodynamic (MHD) are of fundamental and practical significance in industrial and engineering applications. Such types of fluids play a vital role in plasma, fossil fuels, blood flows in the circulatory system, production of glass fiber, petroleum production and magma dynamics, etc. MHD heat transfer has many applications, examples of which are included in biomedical engineering, metallurgical, mental working process (such as magnetic drug target), etc. UCM fluid with MHD effects past a stretching sheet was explored by Abel et al. [1], and it was reported that the wall temperature was escalated for higher values of the Prandtl number. Abbasbanday et al. [2] studied the MHD Oldroyd-B fluid and observed the analytical solution of Falkner-

\footnotetext{
*. Corresponding author.

E-mail address: dmt161001@cust.pk (S.M. Atif)
}

Skan flow. They observed that the velocity components had reverse effects on the parameters of relaxation and retardation times. MHD thermosolutal Marangoni convection of power law fluid was ascertained by Jiao et al. [3], and it was reported that the energy field upsurged and, thus, increased mass Marangoni Number. Hsiao [4] studied the radiative EMHD Carreau nanofluid with activation energy. Wakif et al. [5] reported the numerical analysis of the longitudinal convective rolls in a porous medium. The study was conducted in the presence of the magnetic field, and the medium was filled with nanoparticles. By considering the Arrhenius activation energy and binary chemical reaction, Kumar et al. [6] determined the MHD Carreau fluid. One of the key findings of this study was that the momentum boundary layer thickness upsurged and, then, escalated Weissenberg number. Atif et al. [7] analyzed the MHD squeezed Carreau fluid flow over a sensor surface, and observed that the surface drag was enhanced with an increment in the permeable velocity. For further details, see [8-11].

Eringen $[12,13]$ extended the theory of micropolar 
fluids for the stretching sheet in 1969. Bilal et al. [14] studied the MHD micropolar nanofluid with the variable thermal conductivity. They reported that the gradual increase of thermal radiation parameter caused a decline in the velocity profile. MHD mixed convection micropolar fluid flow through a rectangular duct was studied by Ayano et al. [15], and they observed that the flow reversal increased and velocity decreased as the magnetic field was intensified. Roy and Gorla [16] analyzed the time-dependent MHD micropolar fluid past a wedge, and explored that the magnetic field parameter considerably affected the amplitude of the drag coefficient. Hsiao [17] analyzed the MHD micropolar nanofluid with viscous effects. One of the main observations was that the material parameter and the magnetic number had reverse effects on the velocity and thermal profile. Soundalgekar and Takhar [18] determined the effect of thermal radiation phenomenon on micropolar fluid in continuously moving plates, and found that an increment in the coupling constant enhanced the micro-rotation. Free convective micropolar fluid flow with heat source was explored by Mishra et al. [19], and they argued that heat source resulted in the depreciation of the momentum boundary layer. El-Dabe et al. [20] reviewed the stagnation point of MHD micropolar flow on a vertical plate and found its numerical solution. According to their main conclusion, with the enhancement of the material parameter, the axial velocity declined both in assisting and opposing flows. Atif et al. [21] analyzed the MHD bioconvective micropolar nanofluid, and found that the density profile upsurged as the mass stratification parameter increased. The phenomenon of thermal radiation plays a vital role in the heat and mass transfer, and researchers conducted many studies to highlight its importance. For further study, see details in $[22-26]$.

Choi's concept [27] of nanofluids is widely used by the researchers to make the heat transfer more efficient. Later on, many researchers have incorporated the nanoparticles, which are usually made of carbides, metals, metal oxides or carbon nanotubes with different base fluids to study different phenomena. Sheikholeslami and Rokni [28] studied the convective heat transfer of nanofluid flow in a porous cavity by considering Brownian motion effects, and found that the temperature gradient reduced with an increase in the porosity parameter. Oyelakin et al. [29] explored the Casson nanofluid with slip conditions, and concluded that the temperature field declined as the Dufour parameter increased. Hsiao [30] investigated the stagnation EMHD nanofluid with slip boundary and mixed convection past a stretching sheet. One of the main implications was that the heat transfer increased as the stagnation parameter upsurged. Casson nanofluid flow over a porous surface with viscous effects was studied by Palaniammal and Saritha [31], and they observed that the species concentration distribution showed improvement by the enhancement of nanoparticles volume fraction and the Casson fluid parameter. Madhua et al. [32] worked on timedependent MHD Maxwell nanofluid over a stretching sheet with thermal radiation effects, and reported that the surface drag coefficient was diminished as the Maxwell parameter was intensified. Ferdows et al. [33] discussed the heat and mass transfer characteristics of MHD nanaofluid. It was found that the enhancement of the Eckert number increased the energy profile, while the concentration profile declined gradually. In an exponential sheet, Vijayalaxmi et al. [34] explored the MHD stagnation point of Eyring-Powell nanofluid fluid. Time-dependent tangent hyperbolic fluid flow past a wedge with nanoparticles was ascertained by Atif et al. [35], and they noticed that the concentration profile was enhanced for escalating values of generalized Biot number. For further reading, see [36-40].

In recent decades, many authors have dedicated serious attention to the microstructural effect of different kinds of fluid. Sabeel et al. [41] studied the upper convected Maxwell micropolar fluid with a hyperbolic energy equation. They also considered the thermal radiation and the Joule heating effects. It was observed that the micro-rotation and the temperature profile reduced with the enhancement of the micropolar viscosity ratio parameter. Zahid et al. [42] studied the micropolar Casson fluid with an inclined magnetic field. They mainly found that the fluid velocity was enhanced with an increment in the Eckert number. In the presence of the induced magnetic field, Atif et al. [43] ascertained the MHD micropolar Carreau nanofluid, and reported that the magnetic profile upsurged as the magnetic Prandtl number increased.

To the best of our knowledge, the micropolar fluids with rheological characteristics were not reported in the past. Therefore, the main aim of this paper is to study the behavior of micropolar Carreau nanofluid past a stretching sheet. The shooting method is utilized to solve the modeled problem. The aspects of all physical parameters have been displayed graphically and discussed.

\section{Mathematical formulation}

An incompressible 2D MHD micropolar Carreau nanofluid past a stretching sheet is considered here. The stretching sheet is considered along the horizontal axis, and the vertical axis is normal to the stretching surface. The sheet is stretched with velocity $u^{*}=a x$. The flow is restricted in the region $y>0$. An external magnetic field $B_{0}$ is applied along the positive $y$-axis, as illustrated in Figure 1. The induced magnetic field is ignored due to the assumption of low magnetic 


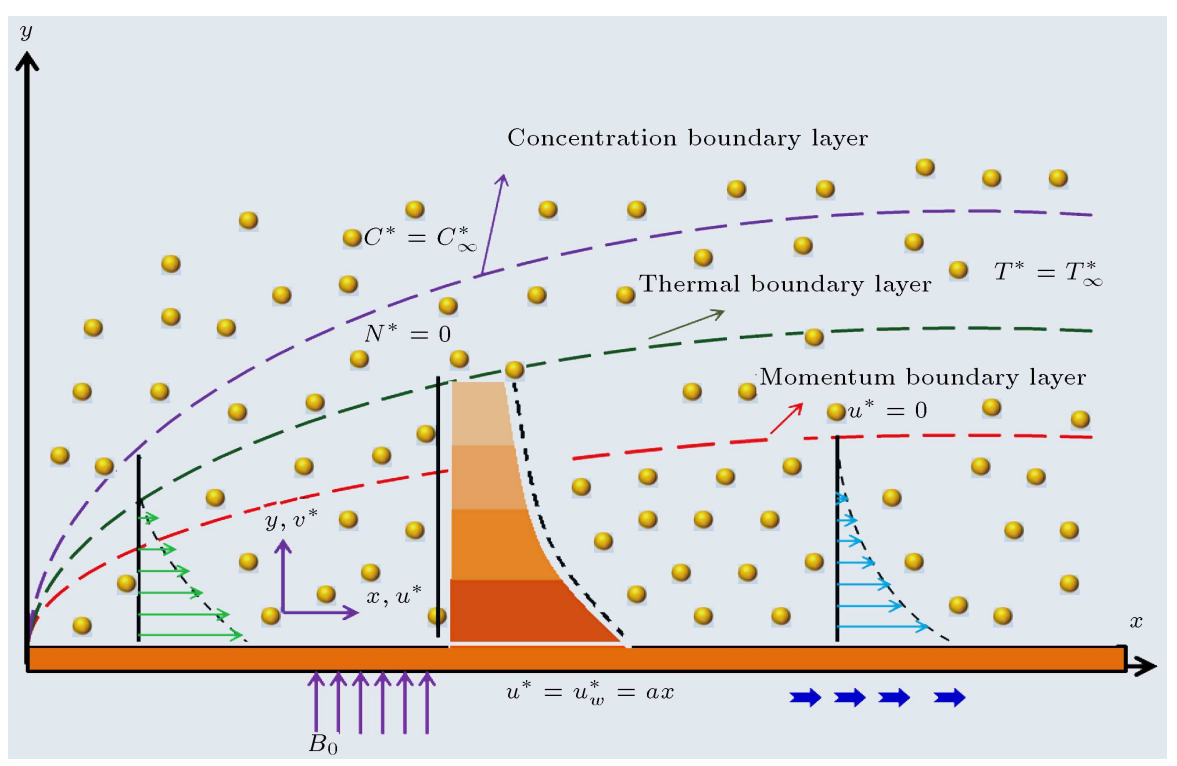

Figure 1. Flow configuration.

Reynolds number. Simulations have been carried out in the presence of thermal radiation, Joule heating, viscous dissipation, and internal heating effects.

Based on the above assumptions, the governing equations of the current modeled problem are as follows $[4,16,17]$ :

$$
\begin{aligned}
& \frac{\partial v^{*}}{\partial y}+\frac{\partial u^{*}}{\partial x}=0 \\
& u^{*} \frac{\partial u^{*}}{\partial x}+v^{*} \frac{\partial u^{*}}{\partial y}=\frac{3 \nu(n-1)}{2} \Gamma^{2}\left(\frac{\partial u^{*}}{\partial y}\right)^{2} \frac{\partial^{2} u^{*}}{\partial y^{2}} \\
& +\left(\nu+\frac{k^{*}}{\rho}\right) \frac{\partial^{2} u^{*}}{\partial y^{2}}+\frac{k^{*}}{\rho} \frac{\partial N^{*}}{\partial y}-\frac{\sigma}{\rho} B_{0}^{2} u^{*}, \\
& u^{*} \frac{\partial N^{*}}{\partial x}+v^{*} \frac{\partial N^{*}}{\partial y}=\frac{\gamma}{(j \rho)_{f}} \frac{\partial^{2} N^{*}}{\partial y^{2}} \\
& -\frac{k^{*}}{(j \rho)_{f}}\left(2 N^{*}+\frac{\partial u^{*}}{\partial y}\right) \text {, } \\
& \left(u^{*} \frac{\partial T^{*}}{\partial x}+v^{*} \frac{\partial T^{*}}{\partial y}\right)=\alpha \frac{\partial^{2} T^{*}}{\partial y^{2}}+\frac{Q_{0}}{\left(\rho C_{p}\right)_{f}}\left(T^{*}-T_{\infty}^{*}\right) \\
& +\frac{\left(\mu+k^{*}\right)}{\left(\rho C_{p}\right)_{f}}\left(\frac{\partial u^{*}}{\partial y}\right)^{2}+\frac{\sigma B_{0}^{2} u^{* 2}}{\left(\rho C_{p}\right)_{f}}-\frac{1}{\left(\rho C_{p}\right)_{f}} \frac{\partial q_{r}}{\partial y} \\
& +\frac{\left(\rho C_{p}\right)_{p}}{\left(\rho C_{p}\right)_{f}}\left[\frac{D_{T}}{T_{\infty}^{*}}\left(\frac{\partial T^{*}}{\partial y}\right)^{2}+D_{B} \frac{\partial^{2} T^{*}}{\partial y^{2}}\right], \\
& u^{*} \frac{\partial C^{*}}{\partial x}+v \frac{\partial C^{*}}{\partial y}=D_{B} \frac{\partial^{2} C^{*}}{\partial y^{2}}+\frac{D_{T}}{T_{\infty}^{*}} \frac{\partial^{2} T^{*}}{\partial y^{2}},
\end{aligned}
$$

whereas the corresponding boundary conditions are as follows:

$$
\begin{aligned}
& u_{w}^{*}=a x, \quad v^{*}=0, \quad N^{*}=0, \quad T^{*}=T_{w}^{*}, \\
& C^{*}=C_{w}^{*} \quad \text { at } \quad y=0, \\
& u^{*}=0, \quad N^{*}=0, \quad T^{*}=T_{\infty}^{*}, \quad C^{*}=C_{\infty}^{*}, \\
& \text { as } y \rightarrow \infty .
\end{aligned}
$$

In the above expressions, $\sigma$ represents the electrical conductivity; $N^{*}$ is the angular velocity; $B_{0}$ is the magnetic field; $\left(C_{p}\right)_{f}$, and $\left(C_{p}\right)_{p}$ denote the specific heat of fluid, and nanoparticles, respectively; $T_{w}^{*}$ and $C_{w}^{*}$ represent the temperature and concentration on the surface, respectively; and $C_{\infty}^{*}$ and $T_{\infty}^{*}$ are the ambient concentration and the ambient temperature, respectively. In Eq. (3), $\gamma$ is given by:

$$
\gamma=\left(\mu+\frac{k^{*}}{2}\right) j,
$$

where $k^{*}$ is the vortex viscosity, and $j=\nu / a$ is the micro-inertia density. In Eq. (4), $q_{r}$ is the Rosseland radiative heat flux and is defined as follows [22-24]:

$$
q_{r}=-\frac{4 \sigma^{*}}{3 \kappa^{*}} \frac{\partial T^{* 4}}{\partial y},
$$

where $\sigma^{*}$ and $\kappa^{*}$ are the Stefan-Boltzmann constant and mean absorption coefficients, respectively. After expanding with Taylor series [44] and ignoring higher power terms, $T^{* 4}$ can be written as follows:

$$
T^{* 4} \approx 4 T_{\infty}^{* 3} T^{*}-3 T_{\infty}^{* 4} .
$$

By using the following transformation [17], Eqs. (2)-(5) can be transformed into the ODEs: 


$$
\begin{array}{ll}
\eta=y \sqrt{\frac{a}{\nu}}, & v^{*}=-f(\eta) \sqrt{a \nu}, \\
u^{*}=a x f^{\prime}(\eta), & N^{*}=a x \sqrt{\frac{a}{\nu}} g(\eta), \\
\theta=\frac{T^{*}-T_{\infty}^{*}}{T_{w}^{*}-T_{\infty}^{*}}, & \phi=\frac{C^{*}-C_{\infty}^{*}}{C_{w}^{*}-C_{\infty}^{*}} .
\end{array}
$$

As a result, Eq. (1) is satisfied identically, and Eqs. (2)(5) yield the following:

$$
\begin{aligned}
& f f^{\prime \prime}-M f^{\prime}+K g^{\prime}-f^{\prime 2} \\
& +\left(1+K+\frac{3(n-1)}{2} \mathrm{We}^{2} f^{\prime \prime 2}\right) f^{\prime \prime \prime}=0, \\
& \left(1+\frac{K}{2}\right) g^{\prime \prime}-K f^{\prime \prime}-g f^{\prime}+f g^{\prime}-2 K g=0, \\
& \left(1+\frac{4}{3} R d\right) \theta^{\prime \prime}+\operatorname{Pr}\left[(1+K) \mathrm{Ec} f^{\prime \prime 2}+f \theta^{\prime}\right. \\
& \left.\quad+M \operatorname{Ec} f^{\prime 2}+N t \theta^{\prime 2}+\delta \theta+N b \theta^{\prime} \phi^{\prime}\right]=0, \\
& \phi^{\prime \prime}+\operatorname{Sc} f \phi^{\prime}+\frac{N t}{N b} \theta^{\prime \prime}=0 .
\end{aligned}
$$

The transformed boundary conditions are as follows:

$$
\begin{array}{ll}
f(\eta)=0, & f^{\prime}(\eta)=1, \quad g(\eta)=0, \\
\theta(\eta)=1, & \phi(\eta)=1, \quad \text { at } \quad \eta=0, \\
f^{\prime}(\eta) \rightarrow 0, & g(\eta) \rightarrow 0,
\end{array}
$$

In the above equations, $\operatorname{Pr}, K, N b, \delta$, We, Ec, $M$, $N t, R d$, and Sc denote the Prandtl number, micropolar constant, Brownian motion parameter, heat generation coefficient, Weissenberg number, Eckert number, magnetic number, thermophoresis parameter, thermal radiation parameter, and Schmidt number, respectively. These parameters are formulated as follows:

$$
\begin{aligned}
& \operatorname{Pr}=\frac{\nu}{\alpha}, \quad K=\frac{k^{*}}{\mu}, \\
& N b=\frac{\left(\rho C_{p}\right)_{p} D_{B}\left(C_{w}-C_{\infty}\right)}{\nu\left(\rho C_{p}\right)_{f}}, \quad \delta=\frac{Q_{0}}{a\left(\rho C_{p}\right)_{f}}, \\
& \mathrm{We}^{2}=\frac{a^{3} x^{2} \Gamma^{2}}{\nu}, \quad \quad \mathrm{Ec}=\frac{a^{2} x^{2}}{\left(C_{p}\right)_{f}\left(T_{w}-T_{\infty}\right)}, \\
& M=\frac{\sigma B_{0}^{2}}{a \rho}, \quad \quad N t=\frac{\left(\rho C_{p}\right)_{p} D_{T}\left(T_{w}-T_{\infty}\right)}{\nu T_{\infty}\left(\rho C_{p}\right)_{f}}, \\
& R d=\frac{4 \sigma^{*} T_{\infty}^{3}}{k \kappa^{*}}, \quad \mathrm{Sc}=\frac{\nu}{D_{B}} .
\end{aligned}
$$

\section{Industrial and engineering quantities of interest}

In industry and engineering, the skin friction coefficient, Nusselt number, and Sherwood number are important quantities.

$$
\begin{aligned}
C_{f} & =\frac{\tau_{w}}{\rho_{f} u_{w}^{2}}, \quad \mathrm{Nu}_{x}=\frac{x q_{w}}{k\left(T_{w}-T_{\infty}\right)}, \\
\mathrm{Sh}_{x} & =\frac{x j_{w}}{D_{B}\left(C_{w}-C_{\infty}\right)} .
\end{aligned}
$$

The wall shear stress, $\tau_{w}$, wall heat flux, $q_{w}$, and wall mass flux, $j_{w}$, are given by:

$$
\begin{aligned}
& \tau_{w}=\mu\left[(1+K) \frac{\partial u^{*}}{\partial y}+\Gamma^{2} \frac{(n-1)}{2}\left(\frac{\partial u^{*}}{\partial y}\right)^{3}\right]_{y=0}, \\
& q_{w}=-k\left[\left(1+\frac{16 \sigma^{*} T_{\infty}}{3 k \kappa^{*}}\right) \frac{\partial T^{*}}{\partial y}\right]_{y=0}, \\
& j_{w}=-D_{B}\left(\frac{\partial C^{*}}{\partial y}\right)_{y=0} .
\end{aligned}
$$

In the non-dimensional form, the skin friction coefficient, Nusselt number, and Sherwood number are as follows:

$$
\begin{aligned}
& C_{f} \sqrt{\operatorname{Re}_{x}}=(1+K) f^{\prime \prime}(0)+\frac{(n-1)}{2} \mathrm{We}^{2}\left(f^{\prime \prime}(0)\right)^{3}, \\
& \mathrm{Nu}_{x} \operatorname{Re}_{x}^{-1 / 2}=-\left(1+\frac{4}{3} R d\right) \theta^{\prime}(0) \\
& \operatorname{Sh}_{x} \operatorname{Re}_{x}^{-1 / 2}=-\phi^{\prime}(0)
\end{aligned}
$$

where $\operatorname{Re}_{x}=\frac{a x^{2}}{\nu}$.

\section{Solution methodology}

The shooting method [44] is implemented to solve the system of Eqs. (8)-(11) subject to the boundary conditions (12). This introduced new variables $\varsigma_{1}=f$, $\varsigma_{4}=g, \varsigma_{6}=\theta$, and $\varsigma_{8}=\phi$ to convert Eqs. (8)-(11) into a system of nine first-order ODEs:

$$
\begin{aligned}
& \varsigma_{1}^{\prime}=\varsigma_{2}, \\
& \varsigma_{2}^{\prime}=\varsigma_{3}, \\
& \varsigma_{3}^{\prime}=\frac{2}{2+2 K+3(n-1) \mathrm{We}^{2} \varsigma_{3}^{2}}\left[\varsigma_{2}^{2}-\varsigma_{1} \varsigma_{3}-K \varsigma_{5}+M \varsigma_{2}\right], \\
& \varsigma_{4}^{\prime}=\varsigma_{5}, \\
& \varsigma_{5}^{\prime}=\frac{2}{2+K}\left[\varsigma_{2} \varsigma_{4}-\varsigma_{1} \varsigma_{5}+K\left(2 \varsigma_{4}+\varsigma_{3}\right)\right],
\end{aligned}
$$




$$
\begin{aligned}
\varsigma_{6}^{\prime}= & \varsigma_{7}, \\
\varsigma_{7}^{\prime}= & -\frac{3 \operatorname{Pr}}{3+4 R d}\left[\varsigma_{1} \varsigma_{7}+M \operatorname{Ec}_{2}^{2}+\delta \varsigma_{6}\right. \\
& \left.+\operatorname{Ec}(1+K) \varsigma_{3}^{2}+N b \varsigma_{7} \varsigma_{9}+N t \varsigma_{7}^{2}\right], \\
\varsigma_{8}^{\prime}= & \varsigma_{9}, \\
\varsigma_{9}^{\prime}= & -\operatorname{Sc} s_{1} \varsigma_{9}-\left(\frac{N t}{N b}\right) \varsigma_{7}^{\prime} .
\end{aligned}
$$

The transformed BCs are as follows:

$$
\begin{aligned}
& \varsigma_{1}=0, \quad \varsigma_{2}=1, \quad \varsigma_{4}=0, \quad \varsigma_{6}=1, \\
& \varsigma_{8}=1, \quad \text { at } \eta=0, \\
& \varsigma_{2} \rightarrow 0, \quad \varsigma_{4} \rightarrow 0, \quad \varsigma_{6} \rightarrow 0, \\
& \varsigma_{8} \rightarrow 0, \quad \text { as } y \rightarrow \infty .
\end{aligned}
$$

Now, this study starts with some choices such as $\varsigma_{3}(0)=c_{1}, \varsigma_{5}(0)=c_{2}, \varsigma_{7}(0)=c_{3}$, and $\varsigma_{9}(0)=c_{4}$ such that the four known $\mathrm{BCs}$ are approximately satisfied for some $\eta \rightarrow \infty$. Classical Newton's method is implemented until the following criteria are met:

$$
\begin{gathered}
\max \left\{\left|\varsigma_{2}\left(\eta_{\max }\right)-0\right|,\left|\varsigma_{4}\left(\eta_{\max }\right)-0\right|,\left|\varsigma_{6}\left(\eta_{\max }\right)-0\right|,\right. \\
\left.\left|\varsigma_{8}\left(\eta_{\max }\right)-0\right|\right\}<10^{-6} .
\end{gathered}
$$

The computations were carried out over the appropriate bounded domain $\eta_{\max }$ instead of $[0, \infty)$.

\subsection{Validation of code}

For the validation of the MATLAB code, the values of $-f^{\prime \prime}(0), g^{\prime}(0),-\theta^{\prime}(0)$, and $-\phi^{\prime}(0)$, reported by Hsiao [17], were reproduced. The computed results are in good agreement with those of Hsiao [17], as presented in Table 1.

\section{Results and discussion}

To examine the impact of sundry parameters on the surface drag, microrotation parameter, the Nusselt number, and the Sherwood number, Table 2 is used. It is noticed that the surface drag is intensified for each power law index, $n$, the magnetic number, $M$, Weissenberg number, We, and material parameter, $K$, which upsurges. The microrotation parameter increases as magnetic number, $M$, and material parameter, $K$, are intensified, whereas it is reduced due to an increment in the Weissenberg number, We, and power index, $n$. The rate of heat transfer increases with the rising of the power law index, $n$, Prandtl number, Pr, Weissenberg number, We, and thermal radiation parameter, $R d$; however, the reverse trend is noticed for the Eckert number, Ec, magnetic number, $M$, Schmidt number, $\mathrm{Sc}$, heat generation coefficient, $\delta$, thermophoresis parameter, $N t$, and Brownian motion parameter, $N b$. The Sherwood number decreases as power law index, $n$, Weissenberg number, We, Prandtl number, Pr, and thermophoresis parameter, $N t$, is increased, whereas it increases as the heat generation coefficient, $\delta$, Brownian motion parameter, $\mathrm{Nb}$, Schmidt number, Sc, thermal radiation parameter, $R d$, Eckert number, Ec, material parameter, $K$, and magnetic number, $M$, increase.

For simulations, the physical parameters are assigned a fixed value since $K=\mathrm{Sc}=0.2, \operatorname{Pr}=7$, $\mathrm{We}=M=1, \mathrm{Ec}=0.02, R d=1, \delta=N t=N b=0.1$, and $n=1.2$. For all computations of this paper, the assigned value of the parameters is fixed, and the varying parameter is displayed in the respective figure.

The impact of Weissenberg number We on velocity profile $f^{\prime}(\eta)$ is captured in Figure 2. The curves of this figure indicate that the fluid motion and momentum boundary layer thickness are heightened when the value of We is higher. Figure 3 indicates the

\begin{tabular}{|c|c|c|c|c|c|c|c|c|c|}
\hline \multirow{2}{*}{$M$} & \multirow{2}{*}{$K$} & \multicolumn{2}{|c|}{$-f^{\prime \prime}(0)$} & \multicolumn{2}{|c|}{$g^{\prime}(0)$} & \multicolumn{2}{|c|}{$-\theta^{\prime}(0)$} & \multicolumn{2}{|c|}{$-\phi^{\prime}(0)$} \\
\hline & & {$[\mathbf{1 7}]$} & Present & {$[\mathbf{1 7}]$} & Present & {$[\mathbf{1 7}]$} & Present & {$[17]$} & Present \\
\hline 0.0 & 0.2 & 0.9098 & 0.90975 & 0.0950 & 0.09500 & 0.4889 & 0.44353 & 0.2035 & 0.20349 \\
\hline 0.5 & & 1.1148 & 1.11438 & 0.1051 & 0.10509 & 0.4476 & 0.40161 & 0.1875 & 0.18746 \\
\hline 1.0 & & 1.2871 & 1.28714 & 0.1121 & 0.11212 & 0.4159 & 0.37234 & 0.1770 & 0.19668 \\
\hline & 0.0 & 1.4142 & 1.41424 & 0 & 0 & 0.3950 & 0.38282 & 0.1711 & 0.25690 \\
\hline & 1.5 & 1.1408 & 1.14077 & 0.2112 & 0.21117 & 0.4407 & 0.38894 & 0.1844 & 0.18436 \\
\hline & 2.0 & 0.7697 & 0.76968 & 0.3586 & 0.35857 & 0.5153 & 0.44292 & 0.2204 & 0.23660 \\
\hline
\end{tabular}
study of the changes in fluid motion caused by material parameter, $K$. It is observed that the enhancement of $K$ causes an increase in $f^{\prime}(\eta)$. Figure 4 shows the analysis of the velocity profile due to changes in the power law index, $n$. An acclivity in $n$ enhances $f^{\prime}(\eta)$. Physically, the higher value of $n$ implies greater viscosity of the fluid, which helps reduce the opposing force and, hence, increase the velocity profile. Figure 5 is drawn to analyze the axial velocity due to the variation

Table 1. Comparison of the presently computed values and those of Hsiao [17]. 
Table 2. Behavior of $-C_{f} \operatorname{Re}_{x}^{1 / 2}, g^{\prime}(0), \mathrm{Nu}_{x} \operatorname{Re}_{x}^{-1 / 2}$, and $-\mathrm{Sh}_{x} \operatorname{Re}_{x}^{-1 / 2}$.

\begin{tabular}{|c|c|c|c|c|c|c|c|c|c|c|c|c|c|c|}
\hline We & $K$ & Pr & $M$ & Ec & $R d$ & $\delta$ & $n$ & $\mathrm{Sc}$ & $N t$ & $N b$ & $-C_{f} \operatorname{Re}_{x}^{\frac{1}{2}}$ & $g^{\prime}(0)$ & $\mathrm{Nu}_{x} \mathrm{Re}_{\boldsymbol{x}}^{-\frac{1}{2}}$ & $-\mathrm{Sh}_{x} \mathrm{Re}_{x}^{-\frac{1}{2}}$ \\
\hline 1 & 0.2 & 7 & 0.1 & 0.02 & 1 & 0.1 & 1.2 & 0.2 & 0.1 & 0.1 & 1.168375 & 0.105988 & 2.436979 & 0.686898 \\
\hline 1.5 & & & & & & & & & & & 1.193765 & 0.104784 & 2.455822 & 0.690971 \\
\hline 2 & & & & & & & & & & & 1.224514 & 0.103348 & 2.477065 & 0.695205 \\
\hline \multirow[t]{30}{*}{1} & 0.2 & & & & & & & & & & 1.168375 & 0.105988 & 2.436979 & 0.686898 \\
\hline & 0.5 & & & & & & & & & & 1.283955 & 0.223544 & 2.776305 & 0.684331 \\
\hline & 1 & & & & & & & & & & 1.446365 & 0.371411 & 3.331984 & 0.677867 \\
\hline & 0.2 & 1.0 & & & & & & & & & 1.168375 & 0.105988 & 0.493420 & -0.015946 \\
\hline & & 5.0 & & & & & & & & & 1.168375 & 0.105988 & 1.986512 & 0.519008 \\
\hline & & 10 & & & & & & & & & 1.168375 & 0.105988 & 2.987811 & 0.894717 \\
\hline & & 7 & 0.1 & & & & & & & & 1.168375 & 0.105988 & 2.436979 & 0.686898 \\
\hline & & & 0.5 & & & & & & & & 1.372167 & 0.114090 & 2.315935 & 0.672148 \\
\hline & & & 1 & & & & & & & & 1.595419 & 0.121424 & 2.181667 & 0.647346 \\
\hline & & & 0.1 & 0.1 & & & & & & & 1.168375 & 0.105988 & 2.160674 & 0.580602 \\
\hline & & & & 0.2 & & & & & & & 1.168375 & 0.105988 & 1.815192 & 0.447693 \\
\hline & & & & 0.3 & & & & & & & 1.168375 & 0.105988 & 1.469599 & 0.314739 \\
\hline & & & & 0.02 & 1.0 & & & & & & 1.168375 & 0.105988 & 2.436979 & 0.686898 \\
\hline & & & & & 2.0 & & & & & & 1.168375 & 0.105988 & 2.817310 & 0.467056 \\
\hline & & & & & 3.0 & & & & & & 1.168375 & 0.105988 & 3.078673 & 0.340501 \\
\hline & & & & & 1 & 0.2 & & & & & 1.168375 & 0.105988 & 2.054790 & 0.540080 \\
\hline & & & & & & 0.3 & & & & & 1.168375 & 0.105988 & 1.610850 & 0.369952 \\
\hline & & & & & & 0.4 & & & & & 1.168375 & 0.105988 & 1.069987 & 0.163305 \\
\hline & & & & & & 0.1 & 2 & & & & 1.240273 & 0.102622 & 2.487335 & 0.697103 \\
\hline & & & & & & & 5.0 & & & & 1.404246 & 0.095460 & 2.574067 & 0.708294 \\
\hline & & & & & & & 10 & & & & 1.568393 & 0.088996 & 2.634106 & 0.708757 \\
\hline & & & & & & & 1.2 & 0.3 & & & 1.168375 & 0.105988 & 2.382129 & 0.562470 \\
\hline & & & & & & & & 0.5 & & & 1.168375 & 0.105988 & 2.295112 & 0.355826 \\
\hline & & & & & & & & 0.7 & & & 1.168375 & 0.105988 & 2.229356 & 0.189220 \\
\hline & & & & & & & & 0.2 & 0.2 & & 1.168375 & 0.105988 & 2.374941 & 1.502700 \\
\hline & & & & & & & & & 0.3 & & 1.168375 & 0.105988 & 2.313962 & 2.272475 \\
\hline & & & & & & & & & 0.4 & & 1.168375 & 0.105988 & 2.254041 & 2.997499 \\
\hline & & & & & & & & & 0.1 & 0.2 & 1.168375 & 0.105988 & 2.347647 & 0.238251 \\
\hline & & & & & & & & & & 0.3 & 1.168375 & 0.105988 & 2.259385 & 0.088850 \\
\hline & & & & & & & & & & 0.4 & 1.168375 & 0.105988 & 2.172220 & 0.014263 \\
\hline
\end{tabular}

of magnetic numbers, $M$. A small enhancement in $M$ causes a decline in the fluid motion. Physically, in electrically conducted fluid, an opposing force (Lorentz force) is produced. This opposing force causes $f^{\prime}(\eta)$ to reduce. Figure 6 portrays the variation of the angular velocity, $g(\eta)$, caused by material parameter, $K$. These curves indicate that $g(\eta)$ increases as $K$ is boosted. Upsurging $K$ means an increment in the viscosity of the fluid, which results in an increase in the angular velocity. Figure 7 shows the variations in $g(\eta)$ due to magnetic number, $M$. A decline in $g(\eta)$ is observed for an enhancement in $M$, which tones up the idea of the opposing force.

Figures 8-17 show variations in the thermal profile, $\theta(\eta)$, due to the nondimensional parameters. Figure 8 shows the behavior of the temperature field for boosting values of the heat generation coefficient, $\delta$. The energy profile goes up when $\delta$ is intensified. To 


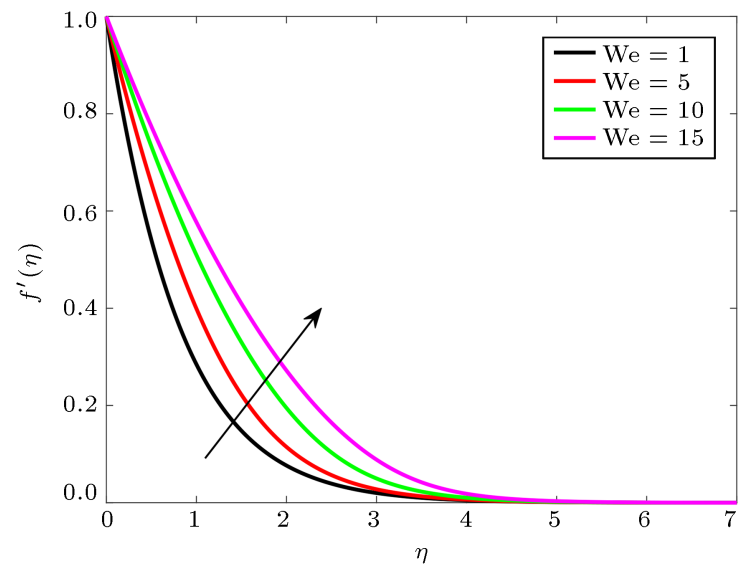

Figure 2. Effect of We on $f^{\prime}(\eta)$.

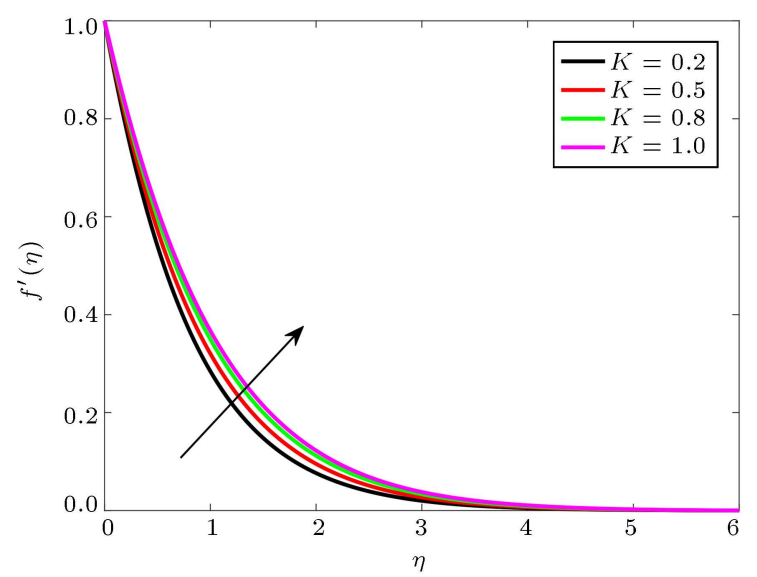

Figure 3. Effect of $K$ on $f^{\prime}(\eta)$.

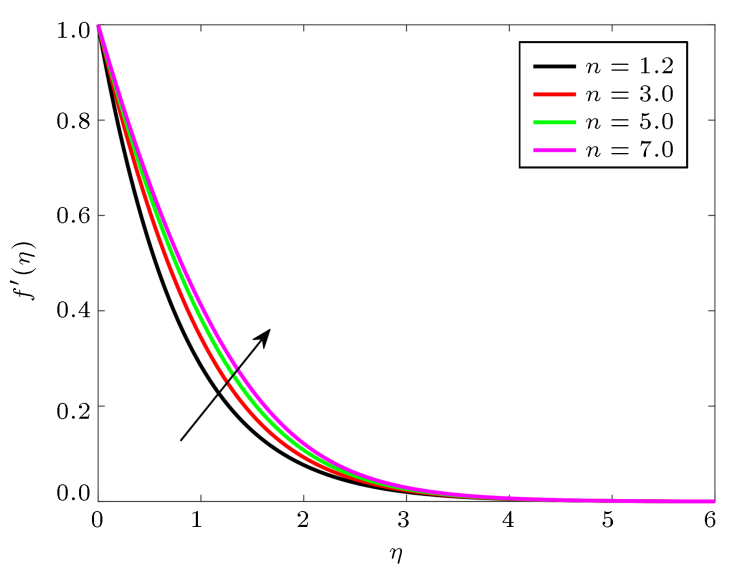

Figure 4. Effect of $n$ on $f^{\prime}(\eta)$.

study the behavior of the viscous dissipation parameter, which is known as Eckert number, Ec, in the energy field, Figure 9 is drawn. An increment in Ec causes a rise in the energy profile. It is because an increase in dissipation improves thermal conductivity, which increases the thermal boundary layer thickness. The impact of the material parameter, $K$, on thermal profile is shown in Figure 10. It is noticed that an increase in $K$

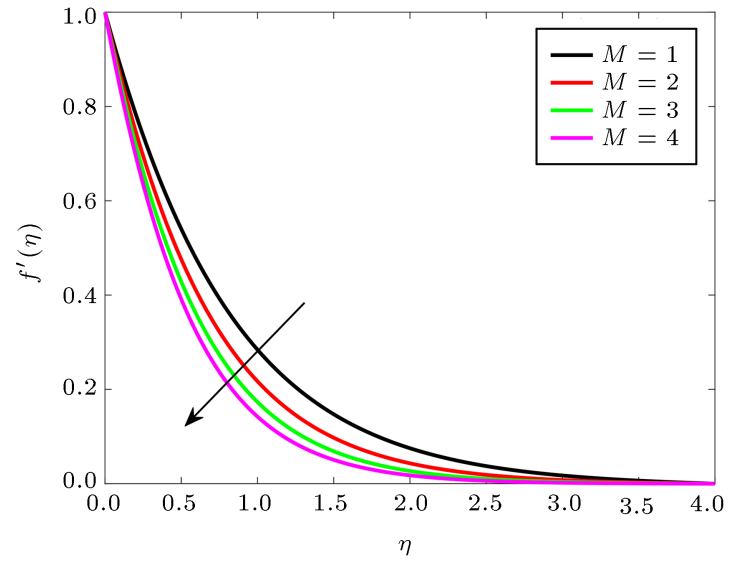

Figure 5. Effect of $M$ on $f^{\prime}(\eta)$.

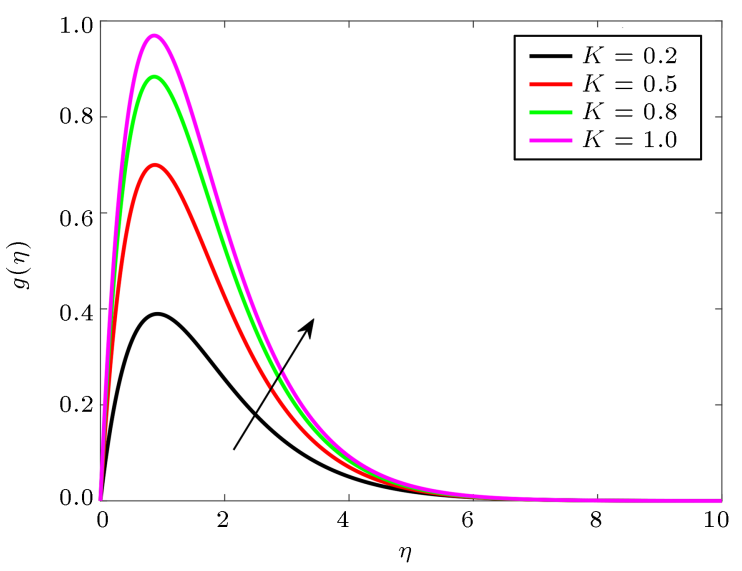

Figure 6. Effect of $K$ on $g(\eta)$.

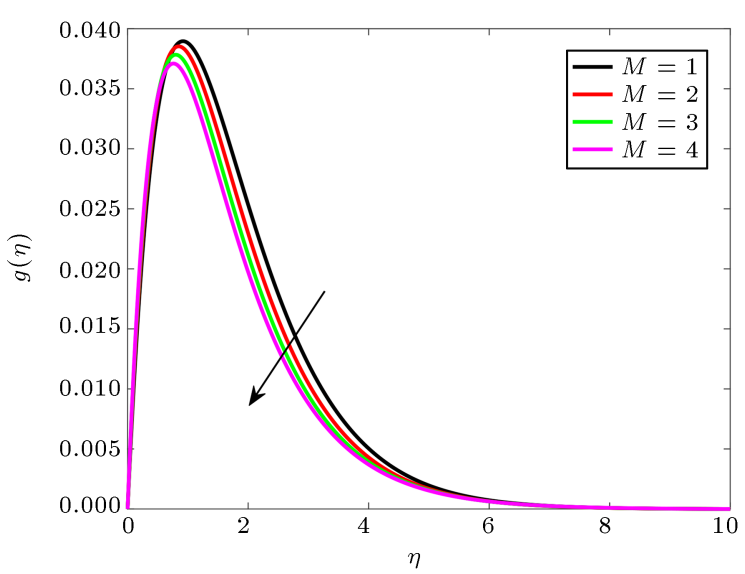

Figure 7. Effect of $M$ on $g(\eta)$.

results in a decline in the thermal field. The variation in the thermal field due to the impact of the magnetic number, $M$, is displayed in Figure 11. The energy field is enhanced as the magnitude of $M$ increases. The resistive force increases with an increment in $M$; as a result, the temperature is intensified. Figure 12 indicates variations in the energy field caused by $\mathrm{Pr}$. Increasing Pr means lowering the thermal conductivity, 




Figure 8. Effect of $\delta$ on $\theta(\eta)$.

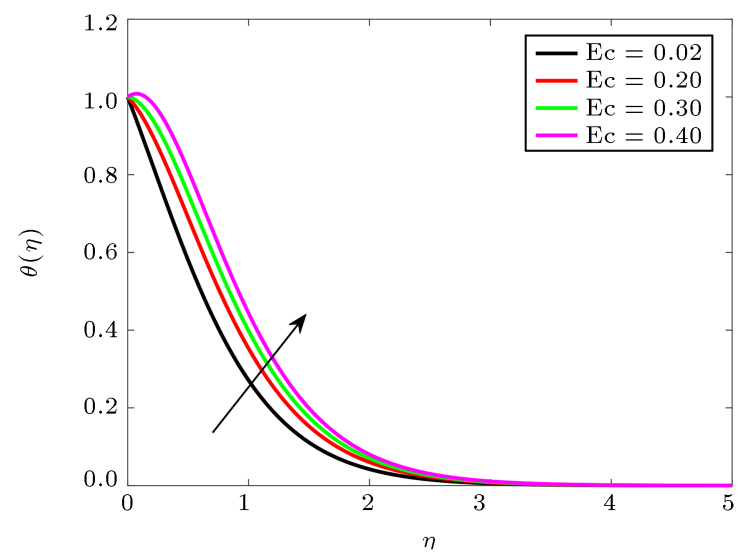

Figure 9. Effect of Ec on $\theta(\eta)$.

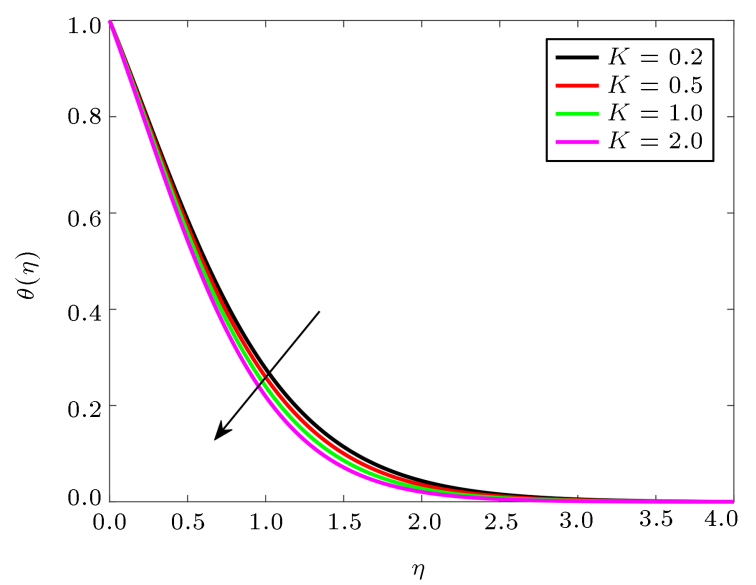

Figure 10. Effect of $K$ on $\theta(\eta)$.

which results in a decline in $\theta(\eta)$. The energy field upsurges for the escalating values of thermal radiation parameter, $R d$, as sketched in Figure 13. The Brownian motion parameter, $\mathrm{Nb}$, represents the random motion of the particles, and Figure 14 depicts that $\theta(\eta)$ is intensified as $N b$ is heightened. Figure 15 shows the changes in the temperature distribution caused by thermophoresis parameter, $N t$. The particles of the

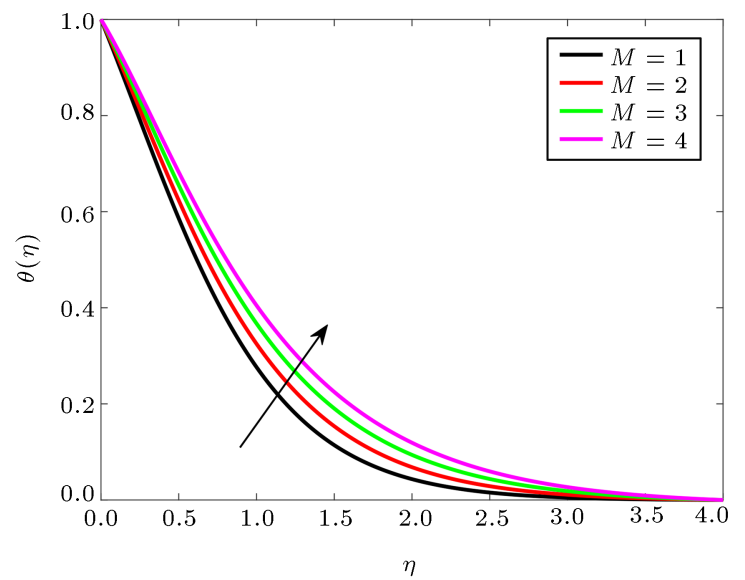

Figure 11. Effect of $M$ on $\theta(\eta)$.

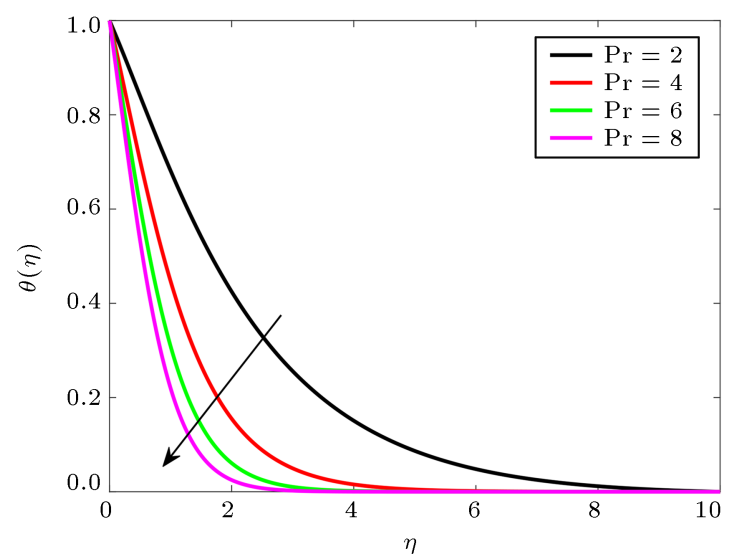

Figure 12. Effect of $\operatorname{Pr}$ on $\theta(\eta)$.



Figure 13. Effect of $R d$ on $\theta(\eta)$.

hotter region are pulled to a less hot region, leading to the enhancement of the energy field. Figure 16 represents the influence of the power law index, $n$, on the temperature. The temperature profile decreases as $n$ decreases. Physically, a gradual increment in $n$ reduces the temperature due to an increase in the nonlinearity. Figure 17 is sketched to investigate the behavior of the temperature due to the variation in the 


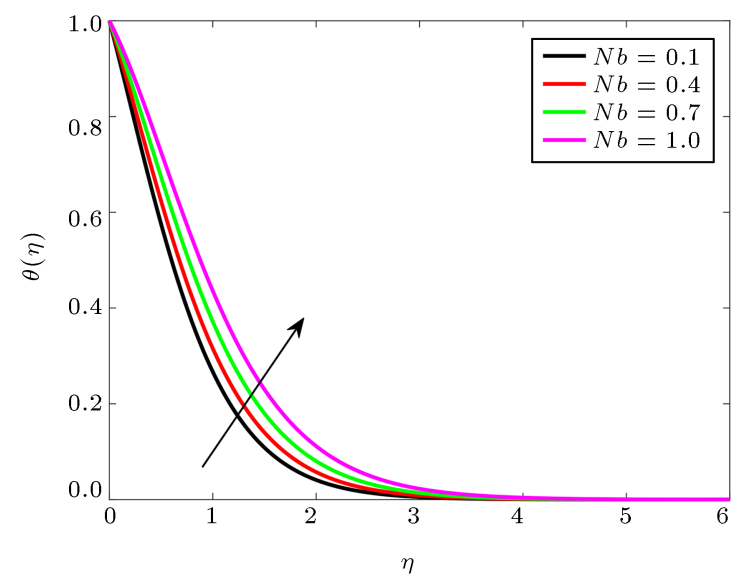

Figure 14. Effect of $N b$ on $\theta(\eta)$.

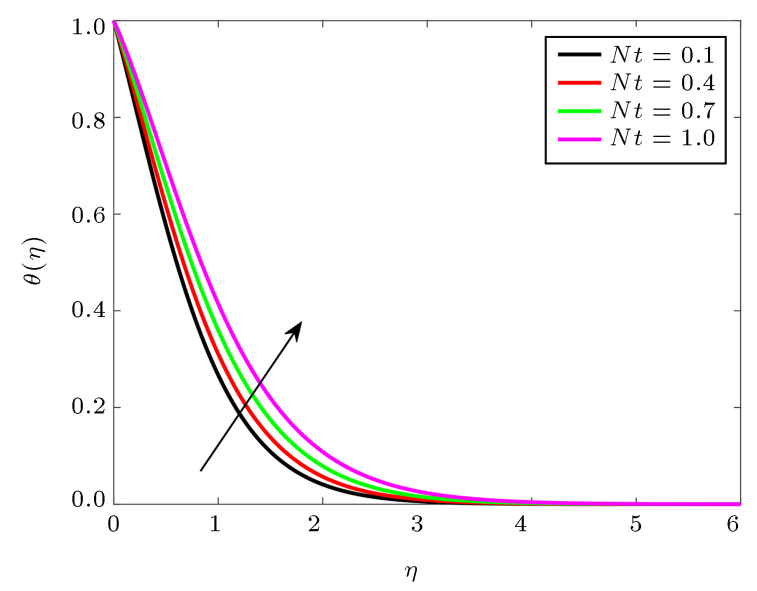

Figure 15. Effect of $N t$ on $\theta(\eta)$.

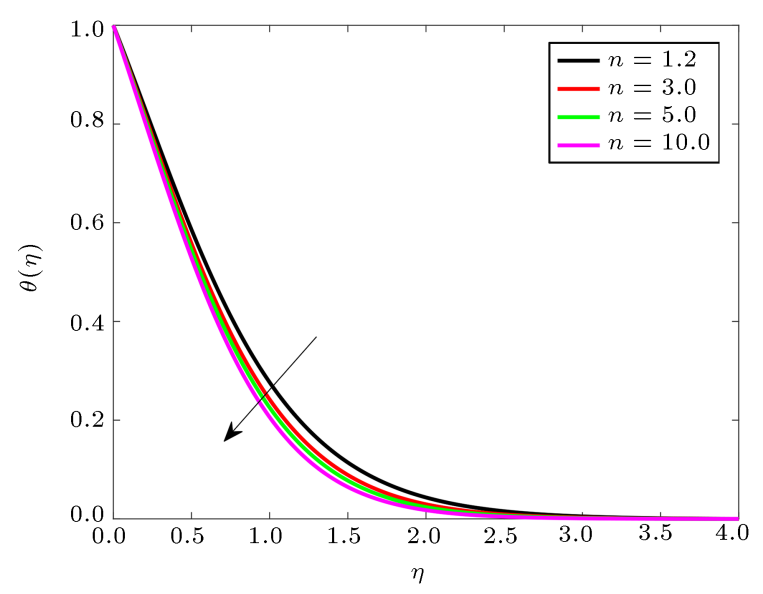

Figure 16. Effect of $n$ on $\theta(\eta)$.

Weissenberg number, We. The energy field lowers as We is enhanced.

Figures 18-25 show the behavior of the concentration profile due to changes in the parameters. Figure 18 shows the variations in the concentration field due to changes in $K$. It is noticed that escalating $K$ causes a decline in the concentration field. Figure 19 shows

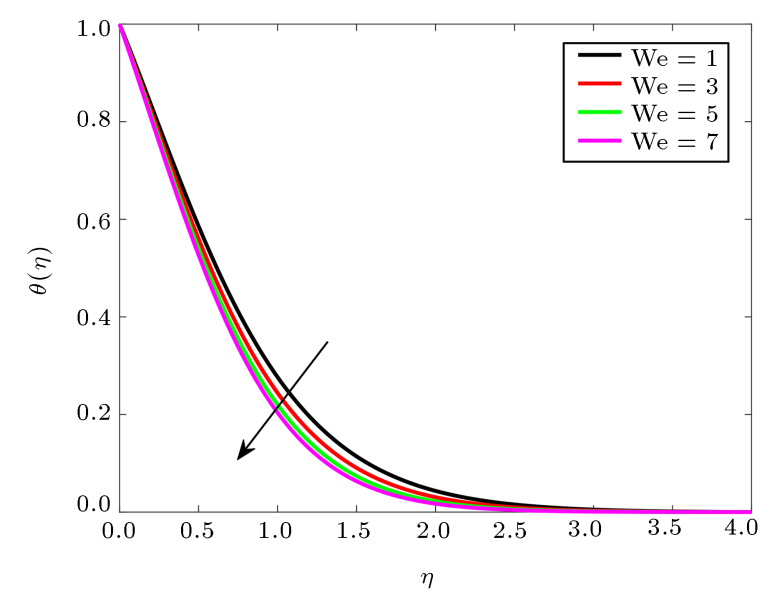

Figure 17. Effect of We on $\theta(\eta)$.

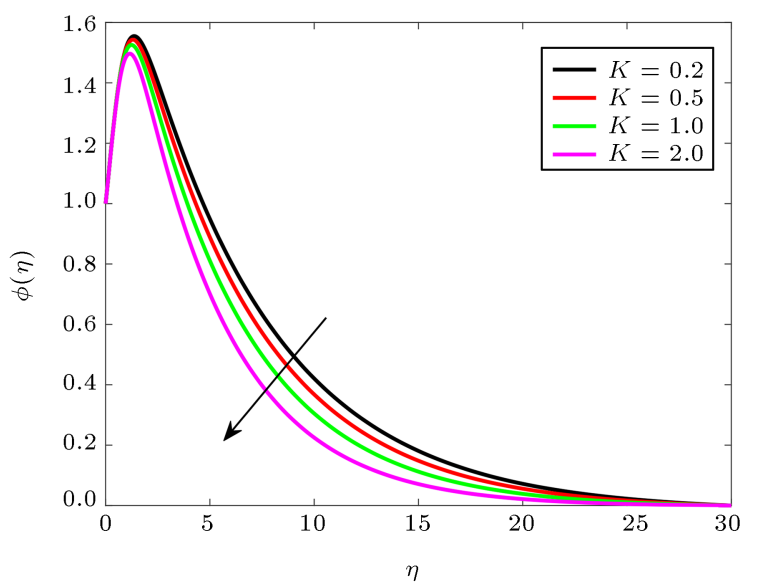

Figure 18. Effect of $K$ on $\phi(\eta)$.

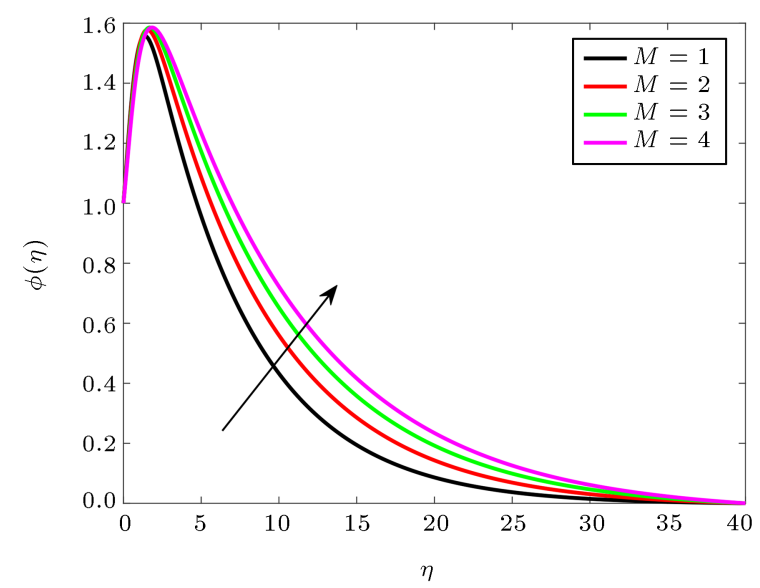

Figure 19. Effect of $M$ on $\phi(\eta)$.

the analysis of the concentration field for the growing values of $M$. These graphs show that an enhancement in $M$ causes an increase in the concentration distribution. Figure 20 shows the behavior of the concentration due to Prandtl number Pr. The concentration profile is enhanced near the surface, whereas it declines when moving away from the surface. Figure 21 is drawn to 


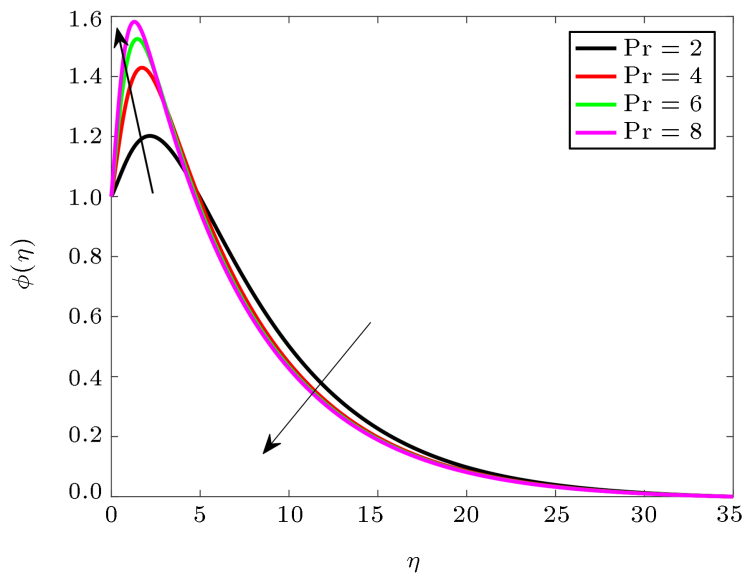

Figure 20. Effect of $\operatorname{Pr}$ on $\phi(\eta)$.

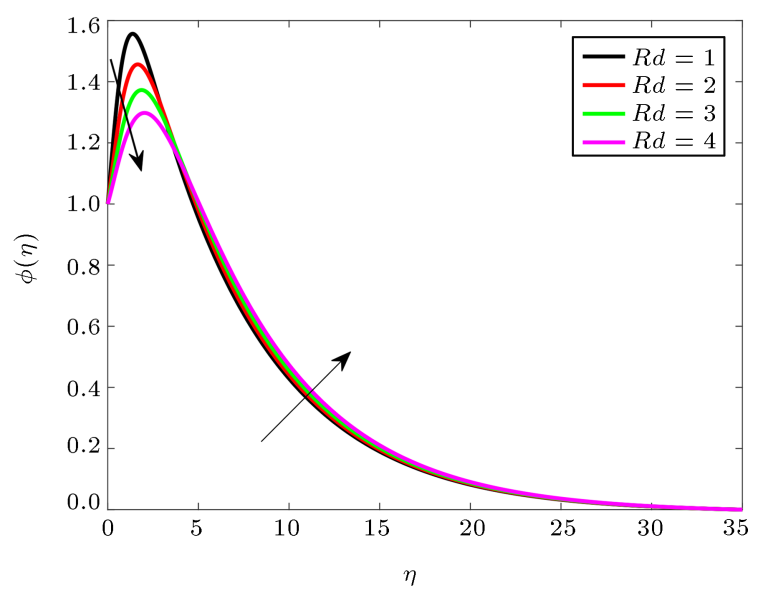

Figure 21. Effect of $R d$ on $\phi(\eta)$.

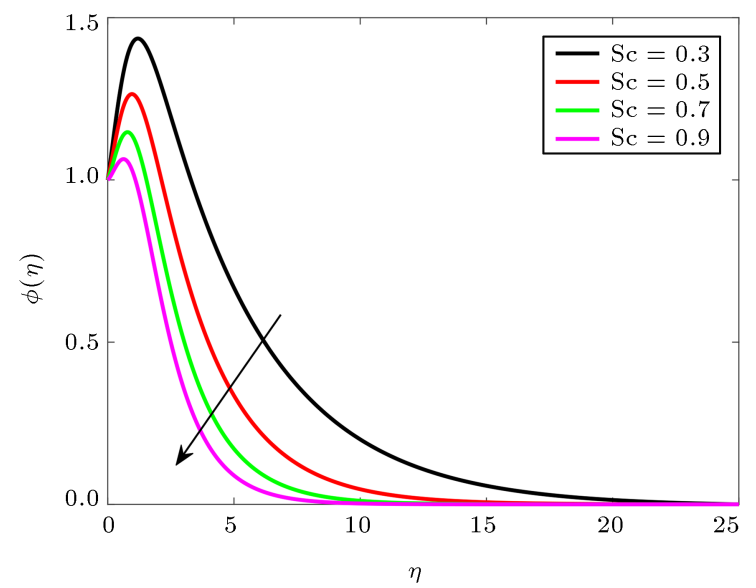

Figure 22. Effect of Sc on $\phi(\eta)$.

ascertain the behavior of $\phi(\eta)$ due to the radiation parameter, $R d$. This graph indicates that $\phi(\eta)$ decreases first near the surface and, then, upsurges while moving away from the surface. Figure 22 explores the behavior of the Schmidt number, Sc, on $\phi(\eta)$. From this graph, it is clear that $\phi(\eta)$ is diminished for escalating

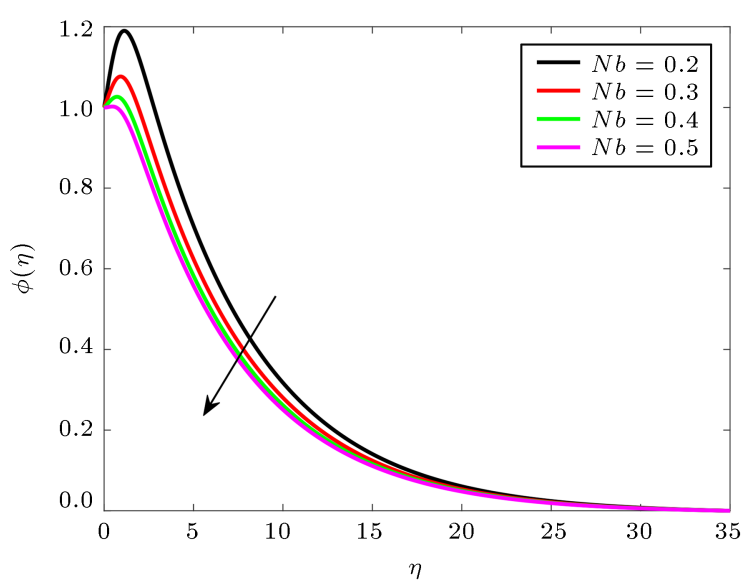

Figure 23. Effect of $N b$ on $\phi(\eta)$.

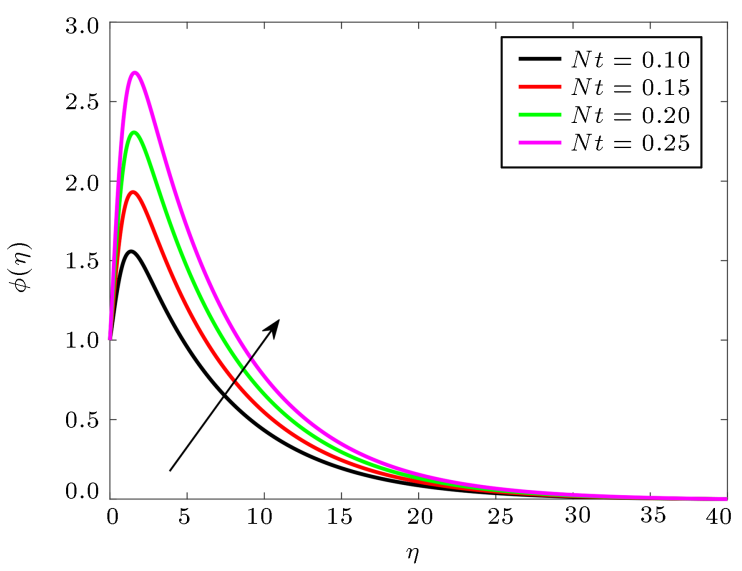

Figure 24. Effect of $N t$ on $\phi(\eta)$.

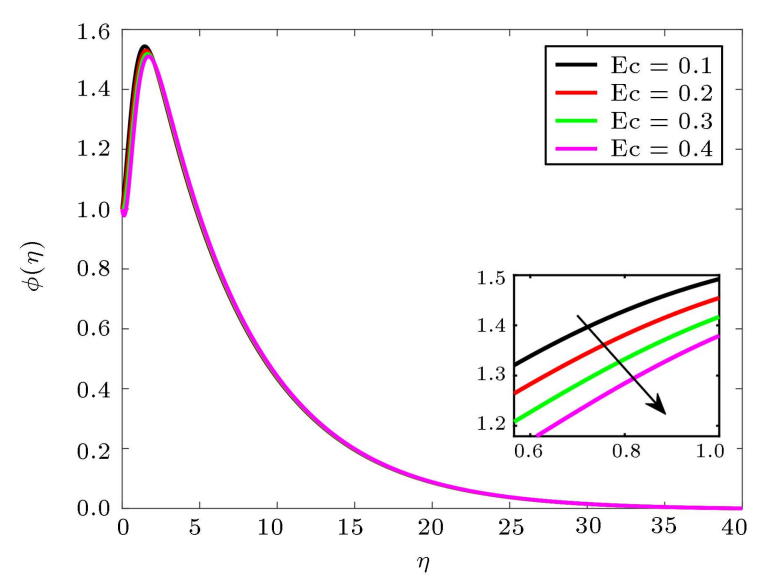

Figure 25. Effect of Ec on $\phi(\eta)$.

values of Sc. A greater value of the Schmidt number represents the lower mass diffusivity. Accordingly, a decrease in $\phi(\eta)$ is noticed. Figure 23 shows that boosting the Brownian motion parameter, $\mathrm{Nb}$, causes a decrease in $\phi(\eta)$. Figure 24 visualizes the effect of the thermophoresis parameter, $N t$, on $\phi(\eta)$. This figure represents that higher values of $N t$ gradually enhance $\phi(\eta)$. Figure 25 observes the influence of the Eckert 


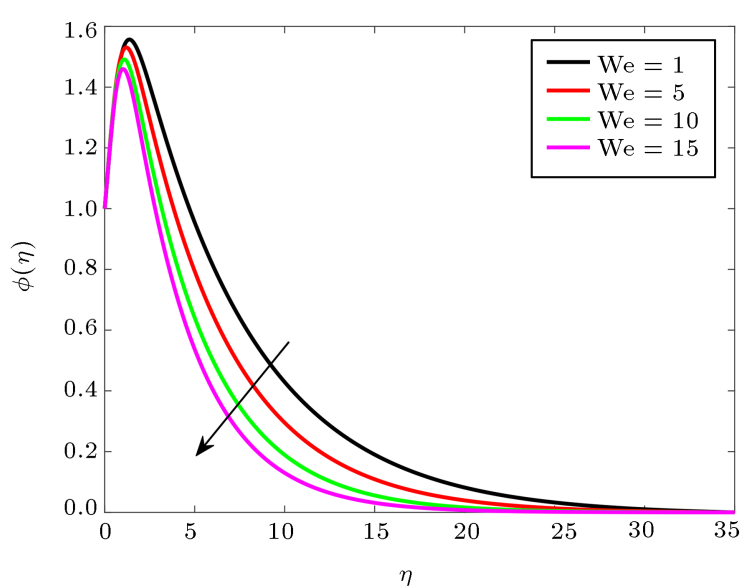

Figure 26. Effect of We on $\phi(\eta)$.

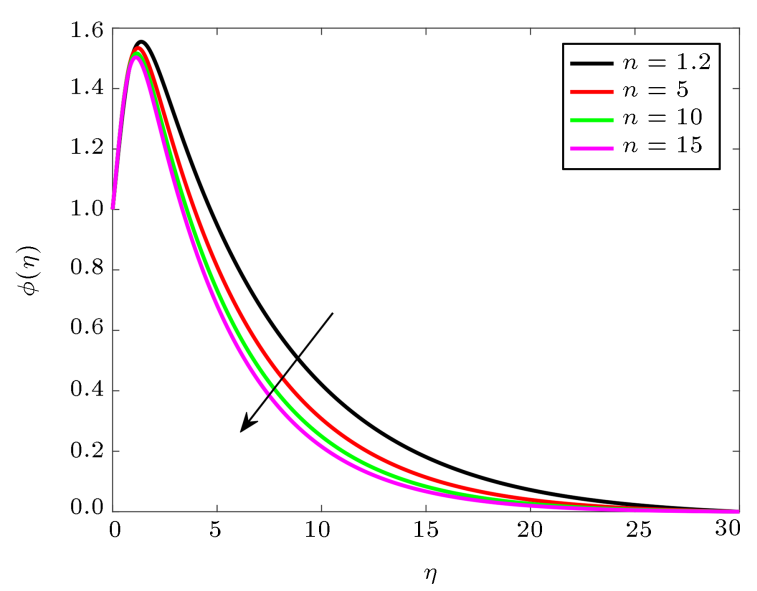

Figure 27. Effect of $n$ on $\phi(\eta)$.

number, Ec, on the concentration distribution, which indicates that $\phi(\eta)$ declines as Ec upsurges. Figure 26 depicts the variation in $\phi(\eta)$ due to the Weissenberg number, We. The concentration profile declines as We upsurges. The influence of the power law index, $n$, on $\phi(\eta)$ is displayed in Figure 27. These curves reflect that boosting $n$ results in an increment in $\phi(\eta)$.

\section{Final remarks}

Two-dimensional MHD micropolar Carreau nanofluid past a stretching sheet was analyzed. The emerging physical parameters were analyzed in the presence of Ohmic heating, linear thermal radiation, internal heating, and viscous dissipation. Some of the main features are:

- The fluid motion was enhanced as the material parameter, $K$, Weissenberg number, We, and power law index, $n$, upsurged;

- The energy field was enhanced as heat generation coefficient, $\delta$, thermal radiation parameter, $R d$, and Eckert number, Ec, increased;
- The material parameter, $K$, and magnetic number, $M$, had opposite effects on the angular velocity;

- The concentration field was enhanced as thermophoresis parameter, $N t$, and the magnetic number, $M$, increased.

\section{Nomenclature}

$B_{0} \quad$ Applied magnetic field (T)

$C^{*} \quad$ Fluid concentration inside the boundary layer $\left(\mathrm{kg} / \mathrm{m}^{3}\right)$

$C_{w}^{*} \quad$ Concentration on the wall surface $\left(\mathrm{kg} / \mathrm{m}^{3}\right)$

$C_{\infty}^{*} \quad$ Fluid concentration outside the boundary layer $\left(\mathrm{kg} / \mathrm{m}^{3}\right)$

$C_{f}^{*} \quad$ Skin friction coefficient

$C_{p}^{*} \quad$ Specific heat $(\mathrm{J} / \mathrm{kgK})$

$D$

Coefficient of mass diffusion $\left(\mathrm{m}^{2} / \mathrm{s}\right)$

$D_{B} \quad$ Brownian diffusion parameter

$D_{T} \quad$ Thermophoresis diffusion parameter

Ec Eckert number

$f \quad$ Reduced stream function

$h_{w} \quad$ Local surface heat flux $\left(\mathrm{W} / \mathrm{m}^{2} \mathrm{~K}\right)$ transfer coefficient

j Microinertia density $\left(\mathrm{m}^{2}\right)$

$j_{w} \quad$ Local mass flux $\left(\mathrm{kg} / \mathrm{m}^{2} \mathrm{~s}\right)$

$k^{*} \quad$ Vortex viscosity $(\mathrm{kg} / \mathrm{ms})$

$k \quad$ Thermal conductivity $(\mathrm{W} / \mathrm{mK})$

$K \quad$ Material parameter $(\mathrm{J} / \mathrm{kgK})$

$M \quad$ magnetic number

$N^{*} \quad$ Dimensionless angular velocity

$\mathrm{Nb} \quad$ Brownian motion parameter

$\mathrm{Nu}_{x} \quad$ Nusselt number

Nt Thermophoresis parameter

$n \quad$ Power law index

Pr Prandtl number

$Q_{0} \quad$ Heat generation coefficient

$q_{w} \quad$ Heat transfer rate (W)

$q_{r} \quad$ Radiative heat flux

$\operatorname{Re}_{x} \quad$ Local Reynolds number

$R d \quad$ Thermal radiation parameter

Sc Schmidt number

$T_{w}^{*} \quad$ Surface temperature (K)

$T_{\infty}^{*} \quad$ Ambient temperature (K)

$t \quad$ Time (s)

$T^{*} \quad$ Boundary layer temperature $(\mathrm{K})$

$u_{w}^{*} \quad$ Characteristics velocity $(\mathrm{m} / \mathrm{s})$ 


$\begin{array}{ll}u^{*} & \text { Velocity in horizontal direction }(\mathrm{m} / \mathrm{s}) \\ v_{w}^{*} & \text { Stretching rate }(\mathrm{m} / \mathrm{s}) \\ v^{*} & \text { Velocity in vertical direction }(\mathrm{m} / \mathrm{s}) \\ \nu & \text { Kinematic viscosity }\left(1 / \mathrm{m}^{2} \mathrm{~s}\right) \\ \rho_{f} & \text { Fluid density } \\ \rho_{p} & \text { Nanoparticle density }\left(\mathrm{kg} / \mathrm{m}^{3}\right) \\ \mu & \text { Dynamic viscosity }(\mathrm{kg} / \mathrm{ms}) \\ \eta & \text { Dimensionless boundary layer thickness } \\ \sigma & \text { Electric charge density } \\ \theta & \text { Dimensionless temperature } \\ \mathrm{We} & \text { Weissenberg number } \\ \left(\rho C_{p}\right)_{f} & \text { Heat capacity of the fluid } \\ \left(\rho C_{p}\right)_{p} & \text { Heat capacity of the nanoparticles } \\ \Gamma & \text { Time constant } \\ \gamma & \text { Spin gradient viscosity } \\ \phi & \text { Dimensionless concentration }\end{array}$

\section{References}

1. Abel, M.S., Tawade, J.V., and Nandeppanavar, M.M. "MHD flow and heat transfer for the upper-convected Maxwell fluid over a stretching sheet", Meccanica, 47(2), pp. 385-393 (2012).

2. Abbasbandy, S., Hayat, T., Alsaedi, A., and Rashidi, M.M. "Numerical and analytical solutions for FalknerSkan flow of MHD Oldroyd-B fluid", International Journal of Numerical Methods for Heat and Fluid Flow, 24(2), pp. 390-401 (2014).

3. Jiao, C., Zheng, L., and Ma, L. "MHD thermosolutal marangoni convection heat and mass transport of power law fluid driven by temperature and concentration gradient", AIP Advances, 5(8), 087160-14 (2015).

4. Hsiao, K.L. "To promote radiation electrical MHD activation energy thermal extrusion manufacturing system efficiency by using Carreau-nanofluid with parameters control method", Energy, 130, pp. 486-499 (2017).

5. Wakif, A., Boulahia, Z., and Sehaqui, R. "Numerical analysis of the onset of longitudinal convective rolls in a porous medium saturated by an electrically conducting nanofluid in the presence of an external magnetic field", Results in Physics, 7, pp. 2134-2152 (2017).

6. Kumar, R.V.M.S.S.K., Kumar, G.V., Raju, C.S.K., Shehzad, S.A., and Varma, S.V.K. "Analysis of Arrhenius activation energy in magnetohydrodynamic Carreau fluid flow through improved theory of heat diffusion and binary chemical reaction", Journal of Physics Communications, 2 (2018).

7. Atif, S.M., Hussain, S. and Sagheer, M. "Effect of thermal radiation and variable thermal conductivity on magnetohydrodynamics squeezed flow of Carreau fluid over a sensor surface", Journal of Nanofluid, 8, pp. $806-816$ (2019).
8. Wakif, A., Boulahia, Z., Mishra, S.R., Rashidi, M.M., and Sehaqui, R. "Influence of a uniform transverse magnetic field on the thermo-hydrodynamic stability in water-based nanofluids with metallic nanoparticles using the generalized Buongiornos mathematical model", The European Physical Journal Plus, 133, pp. 181-197 (2017).

9. Hussain, S. "Finite element solution for MHD flow of nanofluids with heat and mass transfer through a porous media with thermal radiation, viscous dissipation and chemical reaction effects", Advances in Applied Mathematics and Mechanics, 9(4), pp. 904-923 (2017).

10. Kwak, M. and Lkhagvasuren, B. "Global wellposedness for Hall-MHD equations", Nonlinear Analysis, 174, pp. 104-117 (2018).

11. Rahbari, A., Abbasi, M., Rahimipetroudi, I., Sunden, B., Ganji, D.D., and Gholami, M. "Heat transfer and MHD flow of non-Newtonian Maxwell fluid through a parallel plate channel: analytical and numerical solution", Mechanical Sciences, 9, pp. 61-70 (2018).

12. Eringen, A.C. "Theory of micropolar fluids", International Journal of Mathematics and Mechanics, 16, pp. 1-18 (1966).

13. Eringen, A.C. "Theory of thermomicrofluids", Journal of Mathematical Analysis and Applications, 38(2), pp. 480-496 (1972).

14. Bilal, M., Hussain, S., and Sagheer, M. "Boundary layer flow of magneto-micropolar nanofluid flow with Hall and ion-slip effects using variable thermal diffusivity", Bulletin of the Polish Academy of Sciences, 65(3) (2017).

15. Ayano, M.S., Sikwila, S.T., and Shateyi, S. "MHD mixed convection micropolar fluid flow through a rectangular duct", Mathematical Problems in Engineering, 2018 (2018).

16. Roy, N. and Gorla, R. "Unsteady MHD mixed convection flow of a micropolar fluid over a vertical wedge", International Journal of Applied Mechanics and Engineering, 22(2) (2017).

17. Hsiao, K.L. "Micropolar nanofluid flow with MHD and viscous dissipation effects towards a stretching sheet with multimedia feature", International Journal of Heat and Mass Transfer, 112, pp. 983-990 (2017).

18. Soundalgekar, V.M. and Takhar, H.S. "Flow of micropolar fluid past a continuously moving plate", International Journal of Engineering Science, 21(8), pp. 961-965 (1983).

19. Mishra, S.R., Khan, I., Al-mdallal, Q.M., and Asifa, T. "Free convective micropolar fluid flow and heat transfer over a shrinking sheet with heat source", Case Studies in Thermal Engineering, 11, pp. 113-119 (2018). 
20. El-Dabe, N.T., Ghaly, A.Y., Rizkallah, R.R., Ewis, K.M., and Al-Bareda, A.S. "Numerical solution of MHD flow of micropolar fluid with heat and mass transfer towards a stagnation point on a vertical plate", American Journal of Computational Mathematics, 5, pp. 158-174 (2015).

21. Atif, S.M., Hussain, S., and Sagheer, M. "Magnetohydrodynamic stratified bioconvective flow of micropolar nanofluid due to gyrotactic microorganisms", AIP Advances, 9, p. 025208 (2019).

22. Sheikholeslami, M., Ganji, D.D., Javed, M.Y., and Ellahi, R. "Effect of thermal radiation on magnetohydrodynamics nanofluid flow and heat transfer by means of two phase model", Journal of Magnetism and Magnetic Materials, 374, pp. 36-43 (2015).

23. Afify, A.A. "The impacts of thermal radiation and viscous dissipation for the Falkner-Skan flow past a wedge in the presence of nanoparticles suspended in a viscous fluid", Journal of Thermal Science and Technology, 12(2) (2017).

24. Hsiao, K.L. "Combined electrical MHD heat transfer thermal extrusion system using Maxwell fluid with radiative and viscous dissipation effects", Applied Thermal Engineering, 12(5), pp. 1281-1288 (2016).

25. Bilal, M., Sagheer, M., and Hussain, S. "Three dimensional MHD upper-convected Maxwell nanofluid flow with nonlinear radiative heat flux", Alexandria Engineering Journal, 57(3), pp. 1917-1925 (2017).

26. Atif, S.M., Hussain, S., and Sagheer, M. "Effect of viscous dissipation and Joule heating on MHD radiative tangent hyperbolic nanofluid with convective and slip conditions", Journal of the Brazilian Society of Mechanical Sciences and Engineering, 41(4), pp. 189206 (2019).

27. Choi, S.U.S. and Eastman, J.A. "Enhancing thermal conductivity of fluids with nanoparticles", ASME Fluids Engineering, 231, pp. 99-105 (1995).

28. Sheikholeslami, M. and Rokni, H.B. "Magnetic nanofluid flow and convective heat transfer in a porous cavity considering Brownian motion effects", AIP Physics of Fluids, 30(1), 012003-13 (2018).

29. Oyelakin, I.S., Mondal, S., and Sibanda, P. "Unsteady Casson nanofluid flow over a stretching sheet with thermal radiation, convective and slip boundary conditions", Alexandria Engineering Journal, 55(2), pp. 1025-1035 (2016).

30. Hsiao, K.L. "Stagnation electrical MHD nanofluid mixed convection with slip boundary on a stretching sheet", Applied Thermal Engineering, 98(5), pp. 850861 (2016).

31. Palaniammal, S. and Saritha, K. "Heat and mass transfer of a Casson nanofluid flow over a porous surface with dissipation, radiation, and chemical reaction", IEEE Transactions on Nanotechnology, 16(6), pp. 909-918 (2017).

32. Madhua, M., Kishan, N., and Chamkha, A.J. "Unsteady flow of a Maxwell nanofluid over a stretching surface in the presence of magnetohydrodynamic and thermal radiation effects", Propulsion and Power Research, 6, pp. 31-40 (2017).

33. Ferdows, M., Khan, S., Alam, M., and Afify, A. "MHD boundary layer flow and heat transfer characteristics of a nanofluid over a stretching sheet", Acta Univ. Sapientiae Mathematica, 9(1), pp. 140-161 (2017).

34. Vijayalaxmi, T. and Bandari, S. "Stagnation point flow of MHD Eyring-powell nanofluid fluid over exponential stretching sheet with convective heat transfer", Journal of Nanofluids, 6(3), pp. 447-456 (2017).

35. Atif, S.M., Hussain, S., and Sagheer, M. "Heat and mass transfer analysis of time dependent tangent hyperbolic nanofluid flow past a wedge", Physics Letters A, 283(11), pp. 1187-1198 (2019).

36. Garoosi, F., Hoseininejad, F., and Rashidi, M.M. "Numerical study of natural convection heat transfer in a heat exchanger filled with nanofluids", Energy, 109, pp. 664-678 (2016).

37. Wakif, A., Boulahia, Z., and Sehaqui, R. "Numerical study of the onset of convection in a Newtonian nanofluid layer with spatially uniform and non uniform internal heating", Journal of Nanofluids, 6(1), pp. 136148 (2017).

38. Fakour, M., Rahbari, A., Khodabandeh, E., and Ganji, D.D. "Nanofluid thin film flow and heat transfer over an unsteady stretching elastic sheet by LSM", Journal of Mechanical Science and Technology, 32(1), pp. 177183 (2018).

39. Wakif, A., Boulahia, Z., and Sehaqui, R. "A semianalytical analysis of electro-thermohydrodynamic stability in dielectric nanofluids using Buongiornos mathematical model together with more realistic boundary conditions", Results in Physics, 9, pp. 1438-1454 (2018).

40. Wakif, A., Boulahia, Z., Amine, A., Animasaun, I.L., Afridi, M.I., Qasimd, M., and Sehaqui, R. "Magnetoconvection of Alumina - water nanofluid within thin horizontal layers using the revised generalized Buongiorno's model", Frontiers in Heat and Mass Transfer, 10(3) (2019).

41. Sabeel, M., Hammad, M., Batool, S., and Kaneez, H. "Investigation of MHD effects and heat transfer for the upper-convected Maxwell (UCM) micropolar fluid with Joule heating and thermal radiation using a 
hyperbolic heat flux equation", The European Physical Journal Plus, 132(4), pp. 158-170 (2017).

42. Iqbal, Z., Mehmood, R., Azhar, E., and Mehmood, Z. "Impact of inclined magnetic field on micropolar Casson fluid using Keller box algorithm", The European Physical Journal Plus, 132, pp. 175-188 (2017).

43. Atif, S.M., Hussain, S., and Sagheer, M. "Numerical study of MHD micropolar Carreau nanofluid in the presence of induced magnetic field", AIP Advances, 8, p. 035219 (2018).

44. Na, T.Y., Computational Methods in Engineering Boundary Value Problems, 145, Academic Press (1979).

\section{Biographies}

Shahzada Muhammad Atif is a researcher at Capital University of Science and Technology, Islamabad, Pakistan. He received his Master's degree from University of Punjab, Pakistan. His research interests are fluid dynamics, properties of nanofluids, and their heat transfer characteristics.

Shafqat Hussain completed his $\mathrm{PhD}$ degree from Technische Universitat (TU) Dortmund, Dortmund, Germany in 2012. He also worked as a visiting Assistant Professor at Ruhr-Universitat Bochum (RUB), Bochum, Germany. Currently, he is working as an Associate Professor at Capital University of Science and Technology, Islamabad, Pakistan. His research areas are mainly computational fluid dynamics using finite element methods, Krylov subspace, and multigrid iterative methods.

Muhammad Sagheer completed his $\mathrm{PhD}$ degree from Sussex University, England in 2005. Currently, he is the Head of Mathematics Department at Capital University of Science and Technology, Islamabad, Pakistan. His areas of interest include fluid dynamics, computational mathematics, Eigen value problems, and computational biology. 